\title{
Microstructure evolution and dynamic softening behavior of as-forged Ti-43Al-9V-Y-0.2Y alloy under different deformation parameters
}

\author{
X. J. Xu ${ }^{1}$, Q. B. Wang ${ }^{2}$, S. Z. Zhang ${ }^{2}$, C. J. Zhang ${ }^{2}$, S. L. Zhang ${ }^{3}$, F. T. Kong ${ }^{4}$, D. D. Zhu ${ }^{5}$, \\ H. W. Wang ${ }^{2 * *}$
}

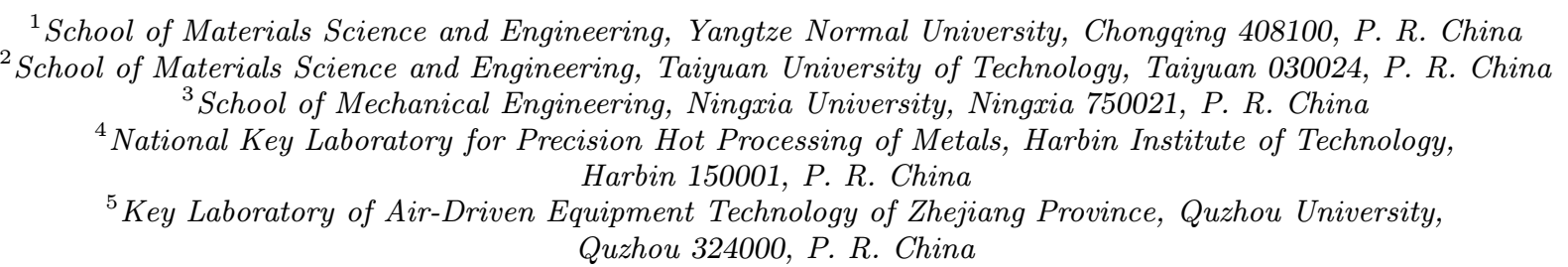

Received 18 September 2019, received in revised form 13 December 2019, accepted 13 December 2019

\begin{abstract}
The dynamic recrystallization (DRX) mechanism and microstructure evolution of the asforged Ti-43Al-9V-Y-0.2Y alloy were investigated by plane strain compression tests under different deformation conditions. The results show that the strain rate has little influence on the microstructure components of present alloy, whereas a large amount of $\gamma$-phase undergoes $\gamma \rightarrow \alpha_{2}$-phase transformation with the total reduction from 40 to $60 \%$ at a constant strain rate. Additionally, DRX and deformation twinning are the primary dynamic softening mechanisms of present alloy. The extent of DRX increases with the decreasing strain rate and increasing total reduction. Meanwhile, twin boundaries (TBs) are observed in $\gamma$-phase of all the samples, which provides coordinated deformation for non-uniform deformation of present alloys. The fraction of TBs reduces from 9.51 to $0.657 \%$ with the increase of strain rate, and rises from 0.657 to $1.05 \%$ with the increase of total reduction, testifying that TBs are connected with DRX nucleation. At the same time, the trend of pseudo twin boundaries (PTBs) content is similar to that of TBs, which is also related to the strain rate and total reduction. Besides, many fine DRX grains located around the TBs and PTBs further explain that the TBs and PTBs promote DRX nucleation. The fiber intensity peak value decreases, and the fiber distribution disperses in the pole figure of $\alpha_{2}$-phase after DRX.
\end{abstract}

Ke y words: TiAl-based alloy, plane strain compression, microstructure characteristic, dynamic softening mechanism, phase transformation

\section{Introduction}

TiAl-based alloys have justifiably attracted much attention as new promising structure materials in aerospace and automotive industries in recent years due to their low density, high specific strength and modulus, superior oxidation resistance, and creep resistance in comparison with other conventional hightemperature alloys [1-4]. Primarily, TiAl-based alloy sheets can be used to manufacture several structural components, such as hollow turbine blades and honeycomb structures [5]. Compared with conventional hot rolling, hot pack-rolling is considered as the most practical approach to obtain TiAl-based alloy sheets because of less tensile stress, slight heat loss and high strain rate insensitivity [6]. The Plansee Company (in Austria) has successfully manufactured a high-quality $\gamma$-TiAl sheet on a conventional mill by a developed powder metallurgy pack rolling process technology [7]. However, oxygen content and cost are the main obsta-

\footnotetext{
*Corresponding author: e-mail address: shuzhizhang@outlook.com

**Corresponding author: e-mail address: $\underline{\text { lntuwhw@126.com }}$
} 
cles of powder metallurgy pack rolling process technology to produce the TiAl sheet [8]. Ingot metallurgy, another hot pack rolling procedure of the TiAl sheet, is a more economical route than powder metallurgy but is hindered by the reduced hot deformability and the narrow hot processing window of TiAl alloys [9]. Therefore, ingot metallurgy pack rolling parameters and the microstructure evolution during rolling should be intensively studied.

Plane strain compression, which is an effective method to optimize rolling parameters and study deformation characteristics, has been widely applied to analyze rolling of steel, light metal alloys, and nonferrous alloys [10-12]. As a simulated experiment of a rolling process, plane strain compression could study the pass deformation, deformation temperature, total deformation, and other deformation parameters in detail. In comparison to pack-rolling processes, the plane strain compression technique can obtain the real or close-to-real high-temperature microstructure [13, 14]. Besides, plane strain compression with low cost can easily adjust the parameters, such as strain rate, reduction per pass, etc.

During hot deformation, the microstructure of the metallic material is influenced by the deformation softening mechanism such as dynamic recovery (DRV), dynamic recrystallization (DRX), and deformation twin. In recent years, extensive endeavors have been carried out on the DRX behavior and deformation twinning of TiAl alloys during hot deformation. For instance, the main DRX nucleation mechanisms could be changed from discontinuous dynamic recrystallization (DDRX) to continuous dynamic recrystallization (CDRX) with strain increase in $\mathrm{P} / \mathrm{M}$ TiAl alloy during hot deformation [15]. However, CDRX is the dominant softening mechanism during hot compression tests for as-cast TiAl alloy [16]. Cui et al. [17] investigated the high-temperature deformation behavior of Ti-43Al-2Cr-2Mn-0.2Y alloy and indicated that lots of sub-boundaries first formed at the early stage of the deformation, while with the increase of deformation, new DRX grains with low-energy configuration formed and grew up. Also, twinning is served as DRX because the occurrence of twinning can compensate for the lack of independent glide systems and promote plastic deformation $[18,19]$. However, most of these studies are unidirectional compressions or conmen forge processes, of which the microstructure evolution and recrystallization behavior are quite different from plane strain compression which has a different strained condition with these unidirectional compressive stress conditions. Microstructure evolution and recrystallization behavior are critically important to pack rolling by ingot metallurgy.

In this work, plane strain compression tests are conducted on the Ti-43Al-9V-0.2Y alloy. This project aims to investigate the influences of strain rate and
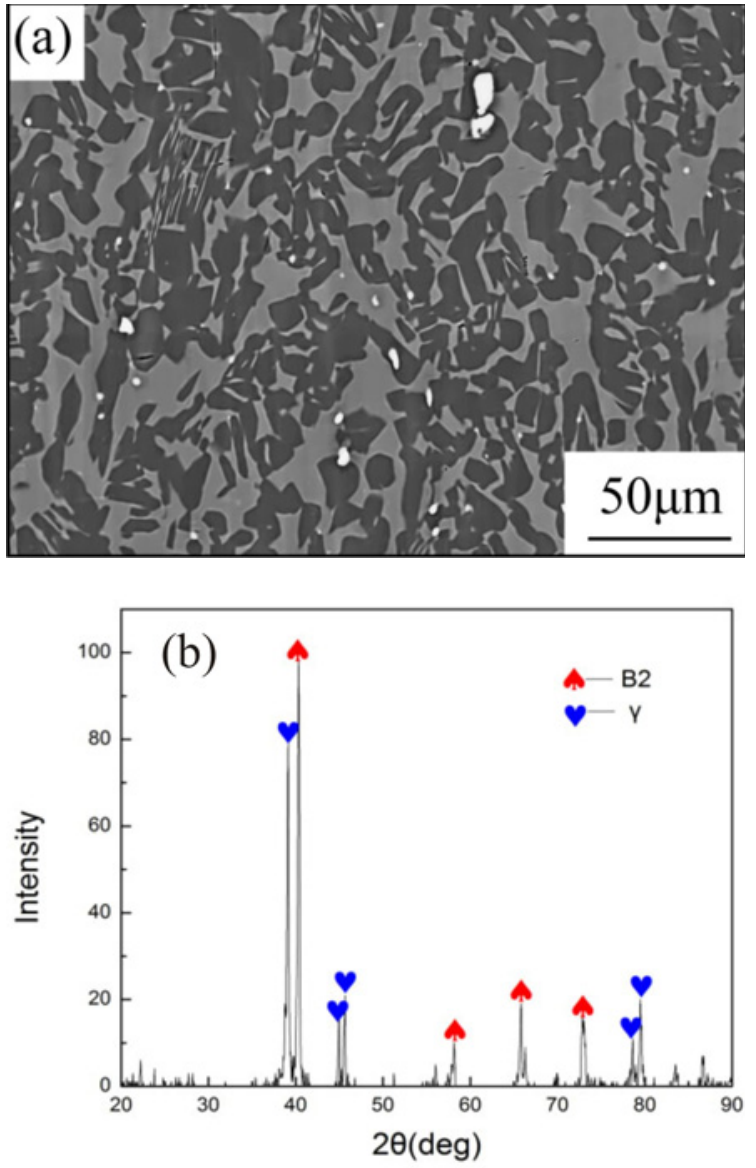

Fig. 1. As-forged microstructure and XRD result of Ti-43Al-9V-0.2Y alloy: (a) as-forged microstructure in BSE mode and (b) XRD result.

total strain on the microstructure evolution, and also, to study the dynamic softening mechanism and phase transformation of Ti-43Al-9V-0.2Y alloy during plane strain compression tests mainly by EBSD techniques.

\section{Experimental procedure}

An ingot with the nominal chemical composition of Ti-43Al-9V-0.2Y (at.\%) was prepared by using an induction skull melting furnace. Subsequently, the ingot was annealed at $900^{\circ} \mathrm{C}$ for $60 \mathrm{~h}$ and hot-isostatically pressed (HIP) for $4 \mathrm{~h}$ at $1250^{\circ} \mathrm{C}$ and $170 \mathrm{MPa}$. After that, a billet was obtained using wire-cut, followed by hot forging. As shown in Fig. 1a, the initial microstructure of the experimental alloy is homogeneous and fine, and is mainly composed of $\beta / \mathrm{B} 2$-phase with gray contrast, $\gamma$-phase with black contrast, and a small amount of yttrium oxide with a white contrast. Figure $1 \mathrm{~b}$ shows the corresponding XRD result, indicating the appearance of $\beta / \mathrm{B} 2$ and $\gamma$, which corresponds to the observation results of Fig. 1a. Noting that 

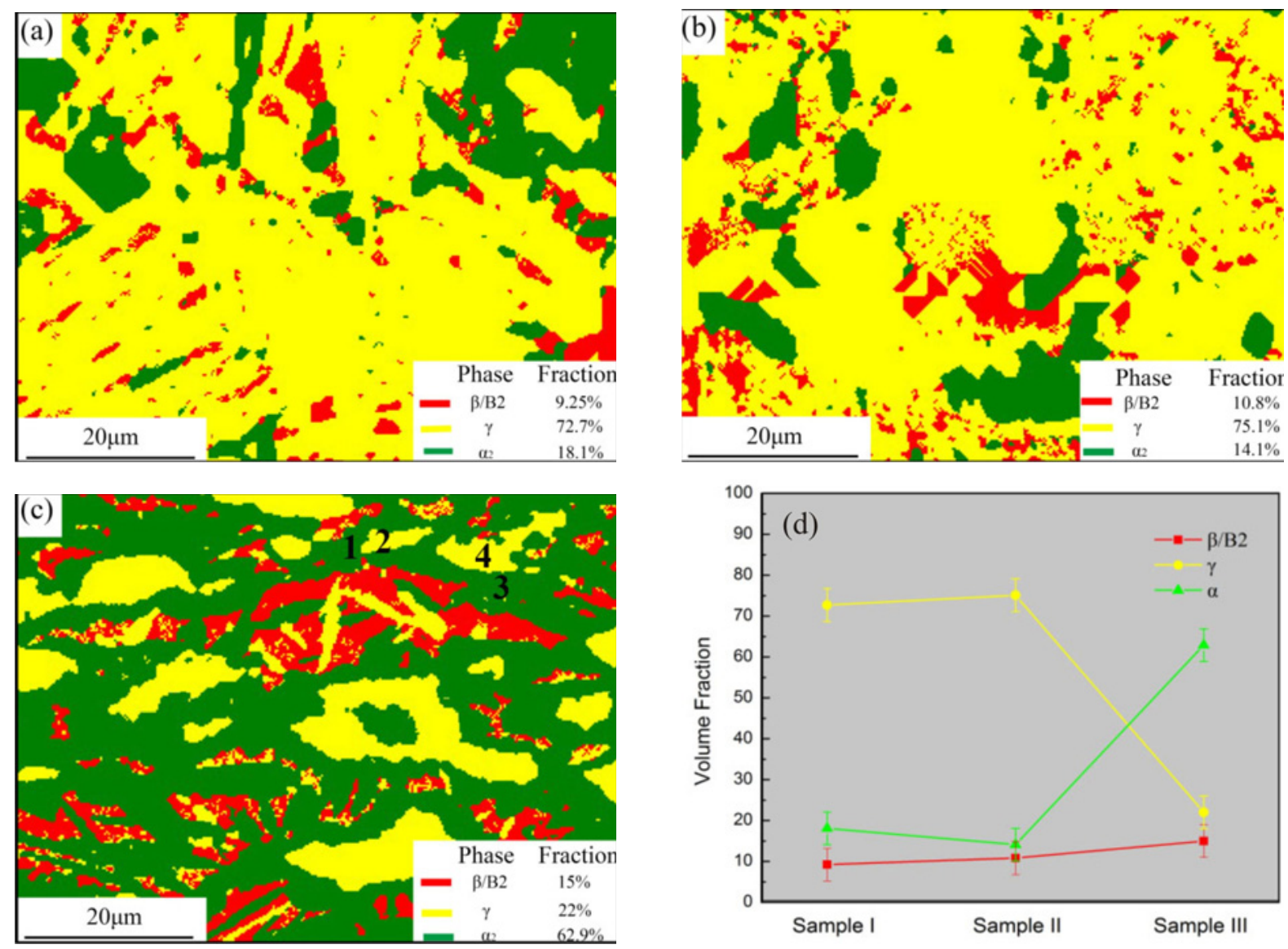

Fig. 2. Phase composition maps of the samples I-III: (a) sample I $\left(40 \%+0.01 \mathrm{~s}^{-1}\right)$, (b) sample II $\left(40 \%+0.05 \mathrm{~s}^{-1}\right)$, (c) sample III $\left(60 \%+0.05 \mathrm{~s}^{-1}\right)$, and $(\mathrm{d})$ volume fraction of different phases.

$\alpha_{2}$-phase cannot be observed because its content is below the detection threshold [20].

The samples with dimensions of $20 \times 8 \times 5 \mathrm{~mm}^{3}$ were cut from the as-forged pancake. The plane strain compression tests were carried out on a Gleeble-3500 thermo-mechanical simulator at $1200^{\circ} \mathrm{C}$ with strain rates of 0.01 and $0.05 \mathrm{~s}^{-1}$. The deformation temperature is in the $\alpha+\beta+\gamma-$ phase-field [2]. The samples were heated up to the target temperature and held for 5 min to homogenize the temperature. They were hot compressed with a reduction of $10 \%$ per pass and with a total engineering strain of 40 and $60 \%$. Between each pass, these samples were heated to compression temperature for $3 \mathrm{~s}$. To minimize the friction of both sides, tantalum foil as a lubricant was placed between samples and dies. Sample compressed at $1200^{\circ} \mathrm{C}$ and with a strain rate of $0.01 \mathrm{~s}^{-1}$ was defined as I, with a total strain of $40 \%$. Sample II was compressed at $1200^{\circ} \mathrm{C}$ with a total strain of $40 \%$; sample III was compressed at $1200{ }^{\circ} \mathrm{C}$ with a total strain of $60 \%$. The sample II and sample III were compressed at the same strain rate of $0.05 \mathrm{~s}^{-1}$ and same temperature of $1200^{\circ} \mathrm{C}$, but with different compression reduction. To maintain the deformation microstructure, the compressed specimens were water quenched. The microstructure of the deformed samples was investigated by back-scattered electron microscopy (SEM-BSE) and electron back-scattered diffraction (EBSD) techniques. The observations were sliced along the compression axis section. The EBSD specimens were electropolished using a solution of $10 \%$ perchloric acid, $30 \%$ butanol and $60 \%$ methanol at $-20^{\circ} \mathrm{C}$ and $30 \mathrm{~V}$. The EBSD measurements were conducted on Quanta 200FEG equipped with EBSD system at scanning interval of $0.15 \mu \mathrm{m}$. The collected data were processed with Channel 5 software provided by HKL technology.

\section{Results and discussion}

\subsection{Phase transformation}

Figure 2 shows the phase composition maps of the samples I-III, including the phase distribution and phase fraction. As shown in Fig. 2a, the sample I is compressed at $1200^{\circ} \mathrm{C}$ with a strain rate of $0.01 \mathrm{~s}^{-1}$, and the total strain is about $40 \%$. Accordingly, samples II and III are compressed at $1200^{\circ} \mathrm{C}$ and strain rate of $0.05 \mathrm{~s}^{-1}$, with a total strain of 40 and $60 \%$, respectively. In Fig. 2a, the volume fractions of $\alpha_{2^{-}}, \gamma-$ 


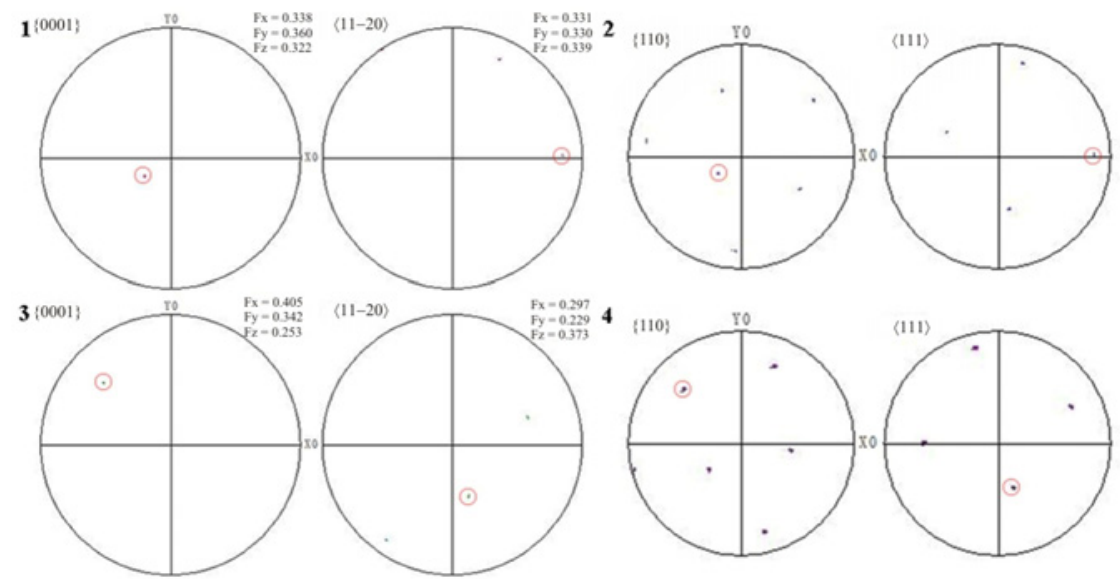

Fig. 3. The pole Figs. 1-4 correspond to the numbered grains or subgrains in Fig. 2 (c), respectively.

and $\beta / \mathrm{B} 2$-phases are $18.1,72.7$, and $9.25 \%$, respectively. Figure $2 \mathrm{~b}$ shows the volume fractions of $\alpha_{2^{-}}, \gamma-$, and $\beta /$ B2-phases change to $14.1,75.1$, and $10.8 \%$, respectively. Comparing with the sample I, the fraction of $\alpha_{2}$-phase volume is smaller in sample II, whereas the volume fractions of $\gamma$ - and $\beta / \mathrm{B} 2$-phases are more significant. With the total reduction increased to $60 \%$ (Fig. 2c), the volume fractions of $\alpha_{2^{-}}, \gamma-$, and $\beta / \mathrm{B} 2-$ -phases are $62.9,22$, and $15 \%$, respectively. Obviously, the fractions of $\alpha_{2}$ - and $\beta / \mathrm{B} 2$-phases in sample III are more extensive than those in sample II. Wang et al. [21] showed that the Shockley partial dislocation $1 / 6<-1-12>$ slips on the primary (111) plane and causes the $\gamma \rightarrow \alpha_{2}$-phase transformation. Therefore, the decrease of $\alpha_{2}$-phase of sample II may be attributed to $\gamma \rightarrow \alpha_{2}$ or B2 $\rightarrow \alpha_{2}$ transformation insufficient for the strain rate increase to $0.05 \mathrm{~s}^{-1}$. On the one hand, the increase of the total reduction under the same strain rate means the increase of the deformation time, which also explains the transformation of $\gamma \rightarrow \alpha_{2}$ proceeds enough. On the other hand, the $\beta / \mathrm{B} 2$-phase, which precipitates from $\alpha_{2}$-phase, is easily hot deformed at elevated temperature [22]. Comparing with the total strain of $40 \%$ of sample II, it reveals that the transformation of $\gamma \rightarrow \alpha_{2}$ in sample III mainly occurs at the later stage of deformation (i.e., the $\gamma \rightarrow \alpha_{2}$-phase transformation occurs when the total reduction is larger than $40 \%$ ). This means that $\gamma \rightarrow \alpha_{2}$ transformation is affected by the strain rate as well as the total reduction. For further verifying the transformation, pole figures display the orientation relationship between different grains or subgrains. Figure 3 displays the analyzed grains (Fig. 2c) and the corresponding pole figures. The specific orientation relationship between the $\alpha_{2}$ and $\gamma$ subgrains is named as Blackburn orientation relationship $\{0001\}_{\alpha} / /\{111\}_{\gamma}$ and $\langle 11-20\rangle_{\alpha} / /<1-10>_{\gamma}[23]$. The perfect Blackburn orientation is observed between grains 1 and 2, 3 , and 4 , suggesting that $\alpha_{2}$ grain nucleates and grows in the $\gamma$-phase.

\subsection{Dynamic recrystallization}

Grain orientation spread (GOS) is the average difference in orientation between the average grain orientation and all measurements in one grain. The GOS value can be presented as [24]:

$\operatorname{GOS}=\left\{\min \left[\cos ^{-1}\left(\left(\operatorname{trace}\left[g_{\text {mean }}\left(f_{i} g^{r}\right)^{-1}\right]-1\right) / 2\right)\right]\right\},(1)$

where $r$ is the $r^{\text {th }}$ measurement point in a grain consisting of $m$ measurements, $g_{\text {mean }}$ is the average orientation of the grain, $g^{r}$ is the orientation of the $r^{\text {th }}$ position, and $f_{i}$ is the appropriate symmetry element yielding the minimum misorientation angle between the average orientation and $r^{\text {th }}$ measurement. The bigger GOS value represents the higher dislocation density. Generally, dislocation can be substantially consumed by dynamic recrystallization (DRX), wherefore GOS, which is associated with a dislocation, can be used to evaluate the extent of DRX [25].

Usually, the first prominent peak is the critical GOS value (CGV) to determine DRX grains [26]. Figure 4 shows the GOS distribution maps of the samples I-III. Consequently, the CGVs of sample I (Fig. 4a), sample II (Fig. 4b), and sample III (Fig. 4c) were $0.95^{\circ}, 0.84^{\circ}$, and $1.05^{\circ}$, respectively. Correspondingly, the DRX volume fractions of the samples I, II, and III were calculated as 94,79 , and $97 \%$, respectively. It is reported that $\gamma$-phase is more comfortable to be dynamically recrystallized than $\alpha$-phase $[13,27]$. Obviously, the contents of DRX grains in sample I (Fig. 4a) and sample III (Fig. 4c) are more than that in sample II (Fig. 4b). As DRX is a thermally activated process, the volume fraction of DRX decreases with the increase of strain rate at a certain total reduction [28, 29]. Meanwhile, the degree of DRX rises with the increase of total reduction. Increasing the total reduction allows sufficient time for DRX at a constant strain rate.

Figure 5 shows the twin boundaries (TBs) and 

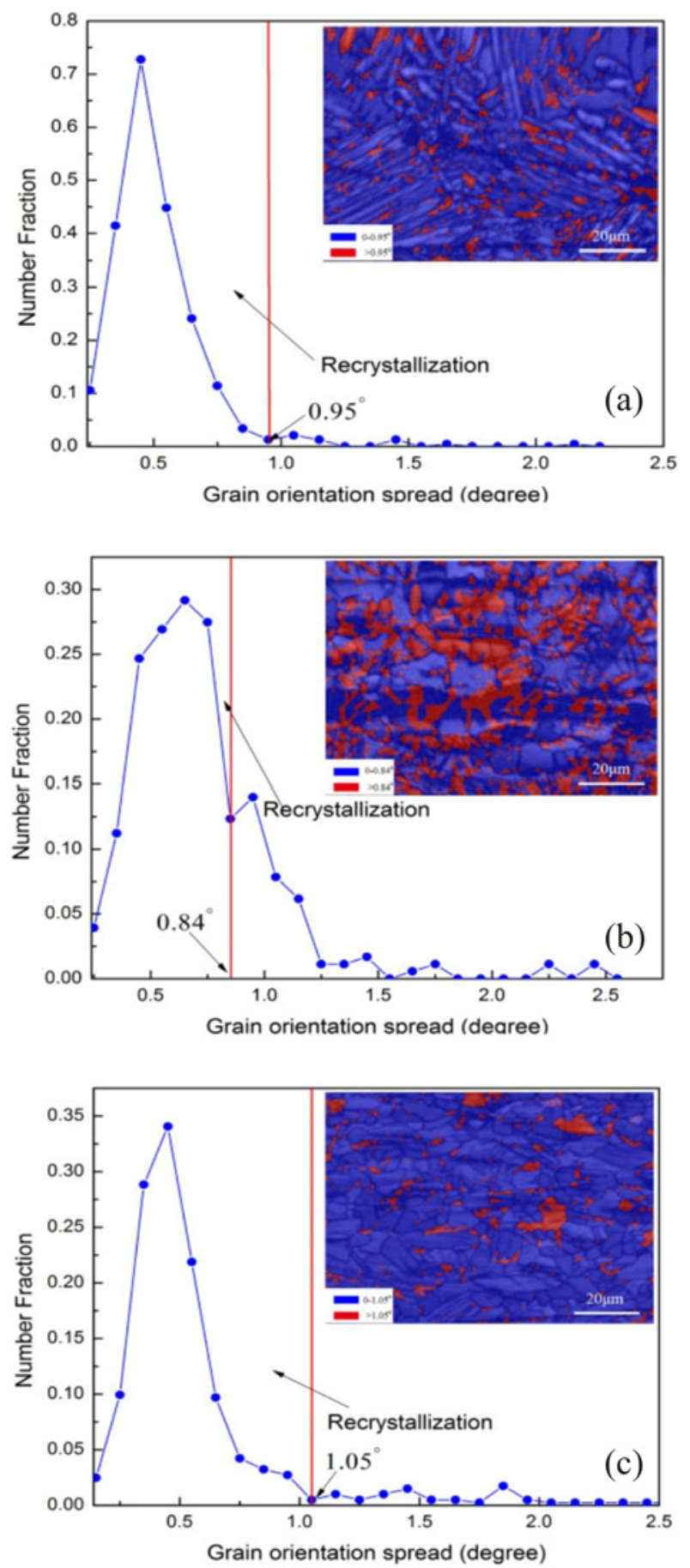

Fig. 4. GOS distribution maps of the samples I-III: (a) sample I $\left(40 \%+0.01 \mathrm{~s}^{-1}\right)$, (b) sample II $(40 \%+$ $\left.0.05 \mathrm{~s}^{-1}\right)$, and (c) sample III $\left(60 \%+0.05 \mathrm{~s}^{-1}\right)$.

pseudo twin boundaries (PTBs) of $\gamma$-phase in the samples I-III. In this figure, TBs with $60 \pm 5^{\circ}<111>$ misorientation angle are marked by bold white lines. The fraction of TBs in the samples I (Fig. 5a), II (Fig. 5b), and III (Fig. 5c) is 9.51, 0.65, and $1.05 \%$, respectively. It is evident that the TBs are mostly dynamically re-
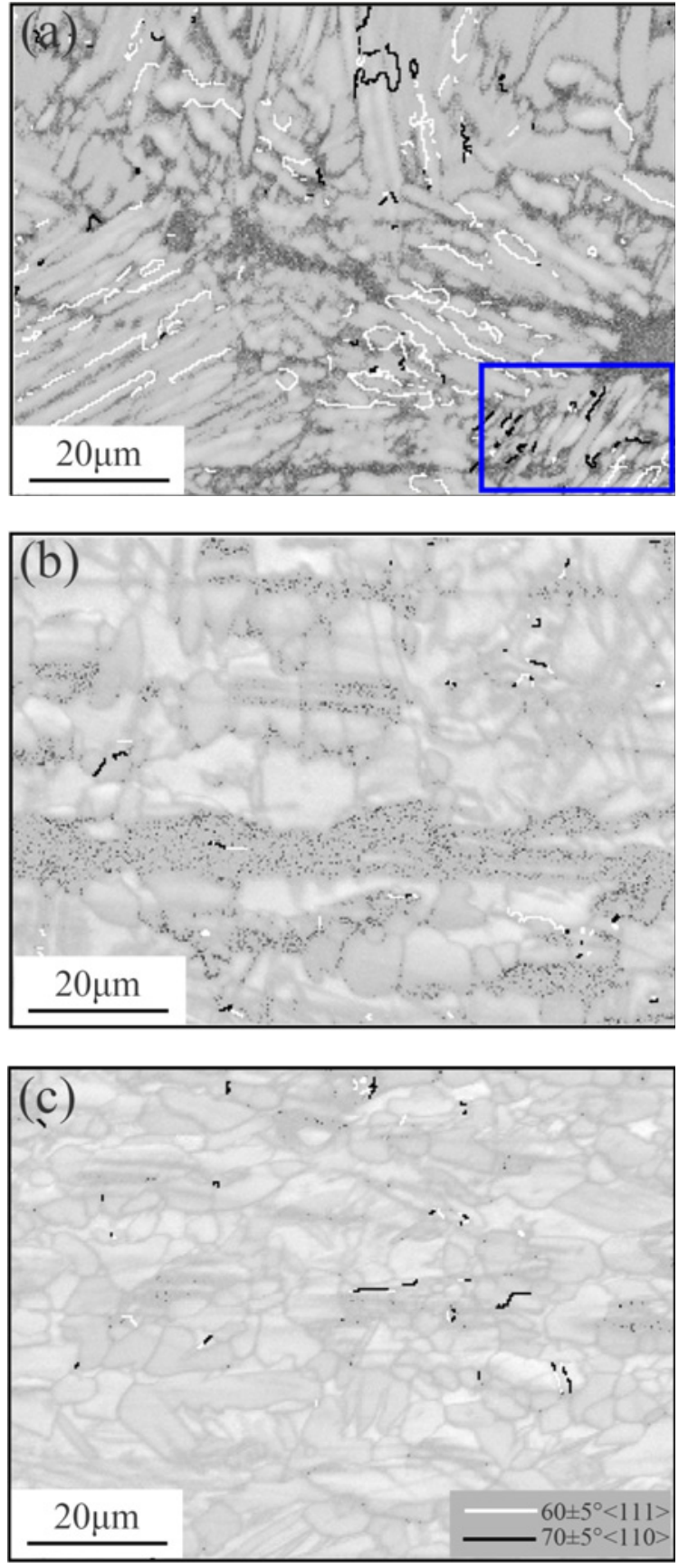

Fig. 5. The TBs and PTBs of $\gamma$-phase in the samples IIII: (a) sample I $\left(40 \%+0.01 \mathrm{~s}^{-1}\right)$, (b) sample II $(40 \%+$ $\left.0.05 \mathrm{~s}^{-1}\right)$, and (c) sample III $\left(60 \%+0.05 \mathrm{~s}^{-1}\right)$.

crystallized $\gamma$ grains. It is illustrated that the $\gamma \rightarrow \alpha_{2}$ occurred in sample III (Fig. 5c) with increasing the total reduction, which accounted for the lower density of TBs in sample II (Fig. 5b). Besides, the fraction of TBs reduces from 9.51 to $0.657 \%$ with the increase of strain rate, and rises from 0.657 to $1.05 \%$ with the increase of total reduction, testifying that TBs are connected with DRX nucleation. Additionally, Jin et al. [30] have noted that a true-twin and a pseudo-twin can 


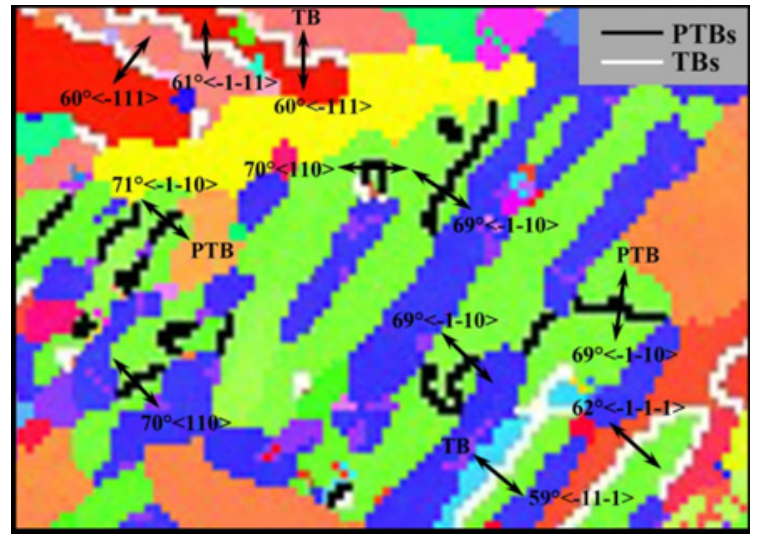

Fig. 6. The local inverse pole figure overlapped with TBs and PTBs is circled by a blue rectangle in Fig. 5 a.

be distinguished only by using $<-110>$ zone diffraction patterns. The bold black lines indicate PTBs with $70 \pm 5^{\circ}<110>$ misorientation angle in Fig. 5. The trend of PTBs content is similar to that of TBs, which is also related to the strain rate and the total reduction. Figure 6 shows the local inverse pole figure overlapped with TBs and PTBs, specifically the area circled by the blue rectangle in Fig. 5a. Also exhibited here are many fine DRX grains located around the TBs and PTBs. These results further explained that TBs and PTBs promoted DRX nucleation. This phenomenon is agreed with the literature [31], which revealed that twinning is the dominant DRX nucleation mechanism in low stacking fault energy crystals.

As well known, $\alpha_{2}$-phase, which possesses larger stacking fault energy than $\gamma$-phase, is prone to dynamic recovery in most cases [30]. However, this does not mean that DRX is impossible in $\alpha_{2}$-phase. Figure 7 shows the misorientation angle distribution of the $\alpha_{2}$-phase in the samples I-III. The grain boundaries with misorientation $\left(15^{\circ}-180^{\circ}\right)$ are defined as high angle grain boundaries (HAGBs) and the low angle grain boundaries (LAGBs) are less than $15^{\circ}$. The fractions of LAGBs in sample I (Fig. 7a), II (Fig. 7b), and III (Fig. 7c) are 11, 4.2, and 2.1\%, respectively, while the fractions of HAGBs of the three samples are $89,95.8$, and $97.9 \%$, respectively. Obviously, the fraction of LAGBs in sample I (Fig. 7a) is larger than that in sample II (Fig. 7b). Take full consideration of different conditions between the sample I and II; the strain rate is the only reason why less LAGBs are presented in sample II. The increase of the strain rate leads to increase the deformation storage energy and DRX can proceed enough, which results in the decrease of LAGBs. Analogously, the fraction of LAGBs in sample II is larger than that in sample III (Fig. 7c). Also, the total reduction leads to more deformation storage energy and has enough time to complete the DRX process. Based on the above analysis, the dom-
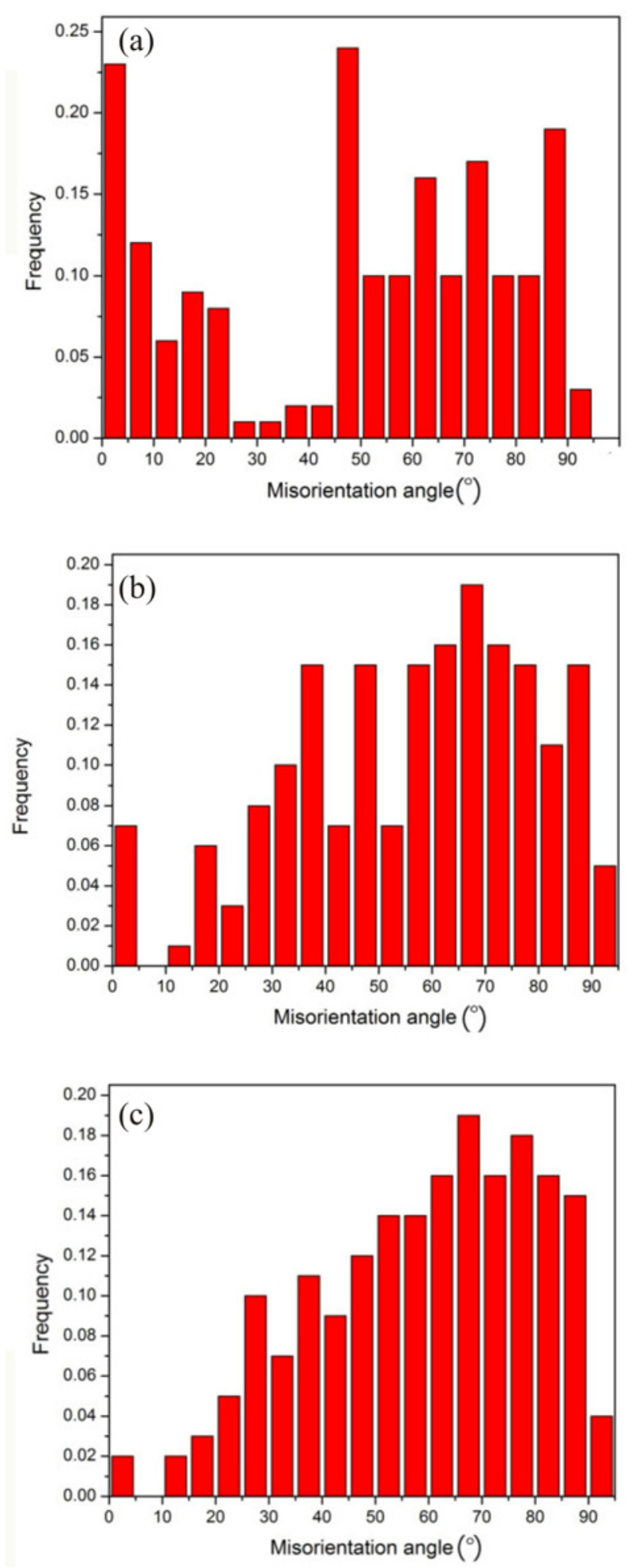

Fig. 7. The misorientation angle distributions of $\alpha_{2}$ phase in the samples I-III: (a) sample I $\left(40 \%+0.01 \mathrm{~s}^{-1}\right)$, (b) sample II $\left(40 \%+0.05 \mathrm{~s}^{-1}\right)$, and (c) sample III $(60 \%+$ $\left.0.05 \mathrm{~s}^{-1}\right)$.

inant softening mechanism in the $\alpha_{2}$-phase is DRX.

Figure 8, the pole figure (PFs) of $\alpha_{2}$-phase, shows the texture evolution of the transformed $\alpha_{2}$-phase in 

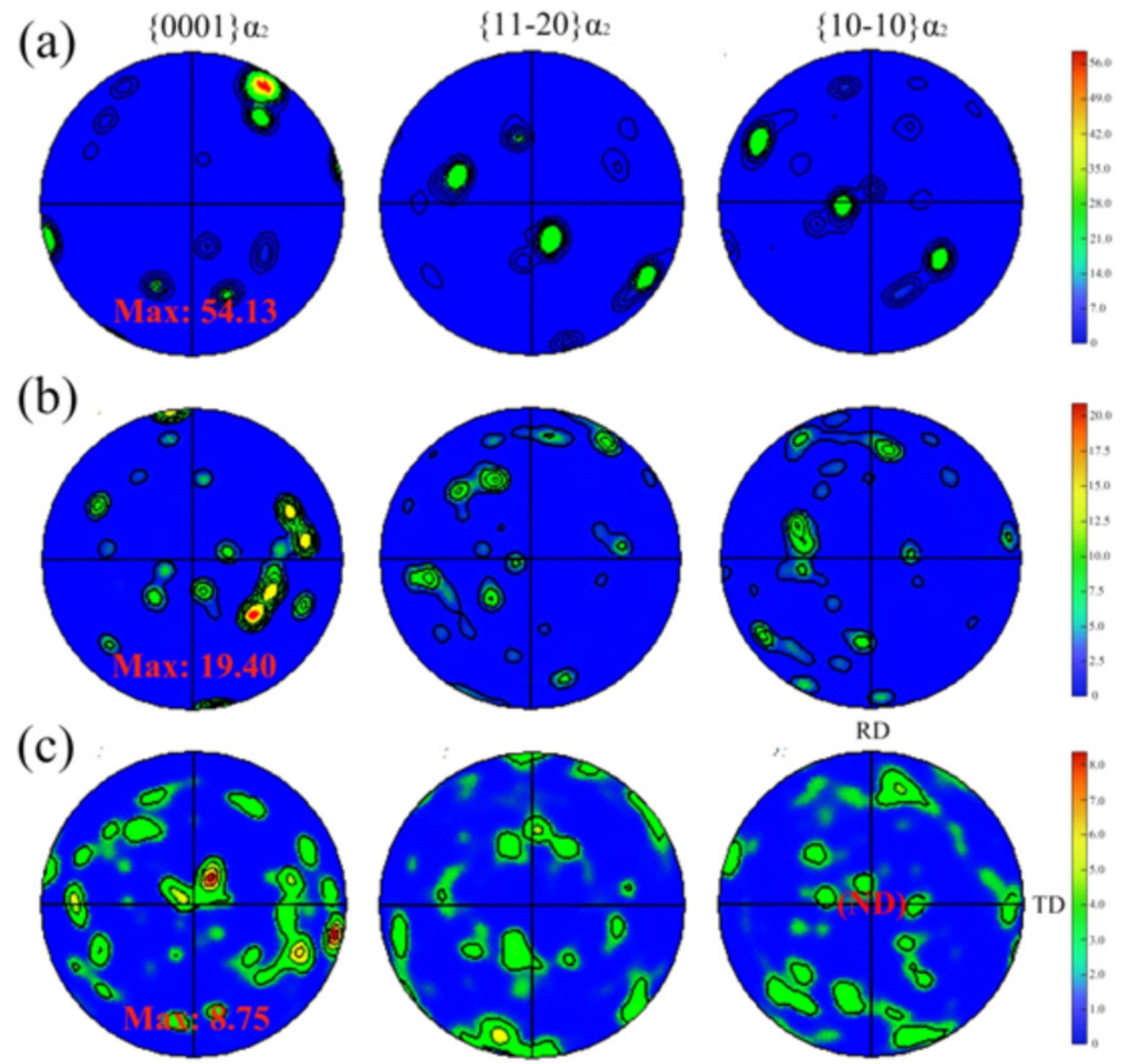

Fig. 8. Pole figure of the samples I-III by different total reductions and strain rates: (a) sample I $\left(40 \%+0.01 \mathrm{~s}^{-1}\right)$, (b) sample II $\left(40 \%+0.05 \mathrm{~s}^{-1}\right)$, and (c) sample III $\left(60 \%+0.05 \mathrm{~s}^{-1}\right)$.

samples I-III. As shown in Fig. 8a, the $<0001>\alpha_{2}$ $\mathrm{PF}$ exhibits strong fiber is perpendicular to ND, of which the maximum fiber intensity reaches 54.13 mud. However, the maximum intensity of fiber is continuously decreased by an increase in total reduction and strain rate. Figures $8 \mathrm{~b}, \mathrm{c}$ clearly depict the fiber intensity peak values of the $<0001>\alpha_{2} \mathrm{PF}$ in samples II-III decrease to $19.40 \mathrm{mud}$ and $8.75 \mathrm{mud}$, respectively. Meanwhile, with total reduction and strain rate increase, the fibers gradually align to several discrete orientations, as indicated by the PFs in Fig. 8. This phenomenon further confirms the analysis above. The increase in strain rate causes deformation storage energy to increase, which leads to an increase in the degree of DRX of $\alpha_{2}$-phase. The DRX process makes the grain orientation tend to be randomly oriented and appears as decreasing the maximum intensity value and dispersing the fiber distribution on the PF. As the amount of total reduction increases, the occurrence of
DRX is further promoted. Therefore, from the sample I to sample III, the maximum intensity keeps decreasing.

\section{Conclusions}

The phase transformation and dynamic recrystallization mechanism of the as-forged Ti-43Al-9V-0.2Y alloy were studied through plane strain compression tests. The following conclusions were drawn:

1. The transformation of $\gamma \rightarrow \alpha_{2}$ is associated not only with the strain rate but also with the total reduction. The transformation occurs at the strain rate of $0.05 \mathrm{~s}^{-1}$ and total reduction of $60 \%$.

2. DRX and deformation twinning are the main dynamic softening mechanisms of the presented alloy. The DRX degree increases with the increase of total reduction or the decrease of the strain rate. 
3. TBs and PTBs are observed in $\gamma$-phase of all the samples. Many fine DRX grains are located around the TBs and PTBs, which explains that the TBs and PTBs promote DRX nucleation.

4. The fiber intensity peak value decreases, and the fiber distribution disperses in the PF of $\alpha_{2}$-phase after DRX.

\section{Acknowledgements}

The financial support from the Nation Natural Science Foundation of China (No. 51604191, 51604159, 51504153, and 51904205), the Natural Science Foundation for Young Scientists of Shanxi Province, China (No. 201701D221075, 201801D221221), China Postdoctoral Science Foundation (No. 2018M641681) and the Special/Youth Foundation of Taiyuan University of Technology (No. 2015QN014) is gratefully acknowledged.

\section{References}

[1] P. Erdely, P. Staron, E. Maawad, N. Schell, J. Klose, S. Mayer, H. Clemens, Effect of hot rolling and primary annealing on the microstructure and texture of a $\beta$-stabilised $\gamma$-TiAl based alloy, Acta Mater. 126 (2017) 145-153. doi:10.1023/A:1004389428278

[2] Y. Chen, L. Cheng, G. Yang, Y. L. Lu, F. B. Han, Deformation behavior of a $\beta$-solidifying TiAl alloy within $\beta$ phase field and its effect on the $\beta \rightarrow \alpha$ transformation, Metals 8 (2018) 605-615. doi: $10.3390 / \operatorname{met} 8080605$

[3] S. Z. Zhang, C. J. Zhang, Z. X. Du, Z. P. Hou, P. Lin, Y. Y. Chen, Microstructure and tensile properties of hot forged high $\mathrm{Nb}$ containing TiAl based alloy with initial near lamellar microstructure, Mater. Sci. Eng. A 642 (2015) 16-21. doi:10.1016/j.msea.2015.06.066

[4] S. Z. Zhang, Y. B. Zhao, C. J. Zhang, J. C. Han, M. J. Sun, M. Xu, The microstructure, mechanical properties, and oxidation behavior of beta-gamma TiAl alloy with excellent hot workability, Mater. Sci. Eng. A 700 (2017) 366-373. doi:10.1016/j.msea.2017.06.025

[5] R. Gerling, A. Bartels, H. Clemens, H. Kestler, F. P. Schimansky, Structural characterization and tensile properties of a high niobium containing gamma TiAl sheet obtained by powder metallurgical processing, Intermetallics 12 (2004) 275-280. doi:10.1016/j.intermet.2003.10.005

[6] X. Liang, Y. Liu, H. Li, Z. Gan, B. Liu, Y. He, An investigation on microstructural and mechanical properties of powder metallurgical TiAl alloy during hot pack-rolling, Mater. Sci. Eng. A 619 (2014) 265-273. doi:10.1016/j.msea.2014.09.091

[7] Y. Liu, X. Liang, B. Liu, W. He, J. Li, Z. Gan, Y. $\mathrm{He}$, Investigations on processing powder metallurgical high-Nb TiAl alloy sheets, Intermetallics 55 (2014) 8089. doi:10.1016/j.intermet.2014.07.013

[8] H. Li, Y. Qi, X. Liang, Z. Zhu, F. Lv, Y. Liu, Y. Yang, Microstructure and high temperature mechanical properties of powder metallurgical Ti-45Al-7Nb-0.3W alloy sheets, Mater. Des. 106 (2016) 90-97. doi:10.1016/j.matdes.2016.05.113
[9] X. Wu, Review of alloy and process development of TiAl alloys, Intermetallics 14 (2006) 1114-1122. doi:10.1016/j.intermet.2005.10.019

[10] N. Keskar, S. Mukherjee, K. V. Mani Krishna, D. Srivastava, G. K. Dey, P. Pant, R. D. Doherty, I. Samajdar, Quantifying the mesoscopic shear strains in plane strain compressed polycrystalline zirconium, Acta Mater. 69 (2014) 265-274. doi:10.1016/j.actamat.2014.01.023

[11] K. D. Molodov, T. Al-Samman, D. A. Molodov, On the diversity of the plastic response of magnesium in plane strain compression, Mater. Sci. Eng. A 651 (2016) 63-68. doi:10.1016/j.msea.2015.10.108

[12] D. W. A. Rees, Plane strain compression of aluminium alloy sheets, Mater. Des. 2012 (39) 495-503. doi:10.1016/j.matdes.2012.03.015

[13] Y. Zong, D. Wen, Z. Liu, D. Shan, $\gamma$-phase transformation, dynamic recrystallization and texture of a forged TiAl-based alloy based on plane strain compression at elevated temperature, Mater. Des. 2016 (91) 321-330. doi:10.1016/i.matdes.2015.11.120

[14] Y. Liang, S. Jiang, Y. Zhang, L. Hu, C. Zhao, Microstructure evolution and deformation mechanism of NiTiFe shape memory alloy based on plane strain compression and subsequent annealing, Mater. Chem. Phys. 2018 (215) 112-120. doi:10.1016/j.matchemphys.2018.05.031

[15] G. Wang, L. Xu, Y. Tian, Z. Zheng, Y. Cui, R. Yang, Flow behavior and microstructure evolution of a $\mathrm{P} / \mathrm{M}$ TiAl alloy during high temperature deformation, Mater. Sci. Eng. A 2011 (528) 6754-6763. doi:10.1016/j.msea.2011.05.071

[16] J. Li, Y. Liu, Y. Wang, B. Liu, Y. He, Dynamic recrystallization behavior of an as-cast TiAl alloy during hot compression, Mater. Charact. 2014 (97) 169-177. doi:10.1016/j.matchar.2014.09.013

[17] N. Cui, F. Kong, X. Wang, Y. Chen, H. Zhou, Hot deformation behavior and dynamic recrystallization of a $\beta$-solidifying TiAl alloy, Mater. Sci. Eng. A 2016 (652) 231-238. doi:10.1016/j.msea.2015.11.097

[18] H. Z. Niu, Y. Y. Chen, F. T. Kong, J. P. Lin, Microstructure evolution, hot deformation behavior and mechanical properties of Ti-43Al-6Nb-1B alloy, Intermetallics 2012 (31) 249-256. doi:10.1016/j.intermet.2012.07.016

[19] T. E. J. Edwards, F. Di Gioacchino, G. Mohanty, J. Wehrs, J. Michler, W. J. Clegg, Longitudinal twinning in a TiAl alloy at high temperature by in situ microcompression, Acta Mater. 2018 (148) 202-215. doi:10.1016/j.actamat.2018.01.007

[20] F. Kong, N. Cui, Y. Chen, X. Wang, N. Xiong, Characterization of hot deformation behavior of asforged TiAl alloy, Intermetallics 2014 (55) 66-72. doi:10.1016/j.intermet.2014.07.010

[21] J. G. Wang, L. C. Zhang, G. L. Chen, H. Q. Ye, T. G. Nieh, Deformation-induced $\gamma-\alpha_{2}$ phase transformation in a hot-forged Ti-45Al-10Nb alloy, Mater. Sci. Eng. A 1997 (240) 287-292. doi:10.1016/S0921-5093(97)00595-9

[22] Y. Y. Zong, D. S. Wen, B. Guo, D. B. Shan, Investigations of hydrogen-promoted $\alpha_{2}$-lamella decomposition of a $\gamma$-TiAl based alloy, Mater. Lett. 2015 (152) 196199. doi:10.1016/j.matlet.2015.03.079 
[23] L. Xiang, B. Tang, X. Y. Xue, H. C. Kou, J. S. Li, Characteristics of the dynamic recrystallization behavior of Ti-45Al-8.5Nb-0.2W-0.2B-0.3Y alloy during high temperature deformation, Metals 2017 (7) 261270. doi: $10.3390 / \operatorname{met} 7070261$

[24] Y. Cao, H. Di, J. Zhang, J. Zhang, T. Ma, R. D. K. Misra, An electron backscattered diffraction study on the dynamic recrystallization behavior of a nickel-chromium alloy $(800 \mathrm{H})$ during hot deformation, Mater. Sci. Eng. A 2013 (585) 71-85. doi:10.1016/i.msea.2013.07.037

[25] B. Kong, G. Liu, D. Wang, K. Wang, S. Yuan, Microstructural investigations for laser welded joints of $\mathrm{Ti}-22 \mathrm{Al}-25 \mathrm{Nb}$ alloy sheets upon large deformation at elevated temperature, Mater. Des. 2016 (90) 723-732. doi:10.1016/i.matdes.2015.11.007

[26] S. Dong, R. Chen, J. Guo, H. Ding, Y. Su, H. Fu, Deformation behavior and microstructural evolution of directionally solidified TiAlNb-based alloy during thermo-compression at 1373-1573 K, Mater. Des. 2015 (84) 118-132. doi:10.1016/j.matdes.2015.06.117
[27] S. Z. Zhang, C. J. Zhang, Z. X. Du, Z. P. Hou, P. Lin, F. T. Kong, Y. Y. Chen, Deformation behavior of high $\mathrm{Nb}$ containing TiAl based alloy in $\alpha+\gamma$ two phase field region, Mater. Des. 2016 (90) 225-229. doi:10.1016/j.matdes.2015.10.080

[28] H. Miura, T. Sakai, R. Mogawa, J. J. Jonas, Nucleation of dynamic recrystallization and variant selection in copper bicrystals, Phil. Mag. 2007 (87) 41974209. doi:10.1080/14786430701532780

[29] Y. C. Lin, X. Y. Wu, X. M. Chen, J. Chen, D. X. Wen, J. L. Zhang, L. T. Li, EBSD study of a hot deformed nickel-based superalloy, J. Alloys Compd. 2015 (640) 101-113. doi:10.1016/j.jallcom.2015.04.008

[30] Z. Jin, G. T. Gray III, On deformation twins and twin-related lamellae in TiAl, J. Mater. Sci. 1998 (33) 7783. doi:10.1023/A:1004389428278 